\title{
Radiometric Study on Posterior Inferior Cerebellar Aneurysms with Special Reference to Accessibility by the Lateral Suboccipital Approach
}

\author{
Akira Yamaura, Hiroshi IsE and Hiroyasu Makino \\ Department of Neurological Surgery, Chiba University School of Medicine, \\ Chiba 280
}

\begin{abstract}
Summary
Radiometric studies were conducted in 21 cases of posterior inferior cerebellar aneurysms and 52 normal subjects to determine the variability of location of the vertebral-posterior inferior cerebellar artery complex in the posterior fossa. Accessibility using a lateral suboccipital approach was evaluated in relation to the radiometric data. Lateral suboccipital openings offered a sufficient surgical field in all cases under minimal retraction of the cerebellum and the results were satisfactory. The range of accessibility of this lateral approach was between 0 to $17 \mathrm{~mm}$ from the midline, 1 to $23 \mathrm{~mm}$ from the foramen magnum, 6 to $16 \mathrm{~mm}$ from the clivus and 35 to $61 \mathrm{~mm}$ from the posterior clinoid process. Postoperative neurological deficits were seen in patients with an aneurysm within $10 \mathrm{~mm}$ of the midline and at more than $13 \mathrm{~mm}$ from the clivus. Advantages of the lateral suboccipital approach are discussed.
\end{abstract}

Key words: Cerebral aneurysm, posterior inferior cerebellar artery, vertebral artery, subarachnoid hemorrhage, posterior fossa, radiometry

\section{Introduction}

The attention of neurosurgeons has been increasingly focussed on surgical treatment of aneurysms of the posterior circulation. The posterior inferior cerebellar artery is a common site of aneurysms in the posterior fossa, second only to the terminal portion of the basilar artery. ${ }^{1,4,9)}$ The significance of anatomical variation of the vertebral artery and of the posterior inferior cerebellar artery has been pointed out by many authors. ${ }^{59}$ Such variation seems to be the main cause of difficulties in direct surgical approach to these aneurysms with their proximity to the brain stem or lower cranial nerves in a very limited space of the posterior fossa. Difficulty in angiographical visualization of aneurysms at this site has also been reported. The subtraction technique, special oblique or submentovertical view were recommended. ${ }^{11)}$ However, there has been no paper dealing with the detailed anatomical location of such aneurysms with reference to surgical accessibility. In the current study, radiometric analysis of the location of the aneurysm was performed to determine the accessibility to the aneurysm by the lateral suboccipital approach. The advantages of this approach are stressed, based on the above radiometric studies. The range of variability of the vertebral-posterior inferior cerebellar artery complex was studied by normal angiography for a base line value.

\section{Materials and Methods}

In the last 4 years, 21 patients with posterior inferior cerebellar aneurysms were hospitalized in the Chiba University School of Medicine and its affiliated hospitals. Except for two cases of peripheral posterior inferior cerebellar aneurysms, all aneurysms were located at the origin of the posterior inferior cerebellar artery on the vertebral artery (Table 1, Figs. 1-3). Of these 21 cases, subarachnoid hemorrhage was the initial sign in 19 cases, and lower cranial nerve palsy and atypical headache were the chief complaints in two other patients (Cases 16 and 18). Both of the latter cases had 
Table 1 Summary of radiometric study and accessibility in posterior inferior cerebellar aneurysms

\begin{tabular}{|c|c|c|c|c|c|c|c|c|c|c|c|}
\hline \multirow[b]{2}{*}{ Case } & \multirow[b]{2}{*}{ Agc } & \multirow[b]{2}{*}{$\operatorname{Sex}$} & \multirow[b]{2}{*}{$\mathrm{SAH}$} & \multirow[b]{2}{*}{ Side } & \multirow[b]{2}{*}{ Type } & \multicolumn{4}{|c|}{ Distance to aneurysm neck $(\mathrm{mm})$} & \multirow[b]{2}{*}{ Surgery } & \multirow[b]{2}{*}{ Remarks } \\
\hline & & & & & & $\begin{array}{c}\text { From } \\
\text { midline } \\
\text { (normal: } \\
10.4+4.8 \text { ) }\end{array}$ & $\begin{array}{c}\text { From } \\
\text { foramen } \\
\text { magnum } \\
\text { (normal: } \\
12.1 \pm 7.0 \mathrm{~mm} \text { ) }\end{array}$ & $\begin{array}{c}\begin{array}{c}\text { From } \\
\text { clivus } \\
\text { (normal: }\end{array} \\
12.5 \pm 4.0 \mathrm{~mm} \text { ) }\end{array}$ & $\begin{array}{c}\text { From } \\
\text { post. } \\
\text { clinoid } \\
\text { (normal: } \\
46.2 \pm 9.7 \mathrm{~mm} \text { ) }\end{array}$ & & \\
\hline \multicolumn{12}{|l|}{ Saccular } \\
\hline 1. & 55 & $\mathrm{~F}$ & + & $\mathrm{L}$ & A & 14 & 23 & 15 & 35 & neck clipping & sitting \\
\hline 2. & 53 & $\mathrm{~F}$ & + & $\mathbf{L}$ & A & 3 & 12 & 13 & 47 & neck clipping & \\
\hline 3. & 51 & $\mathbf{M}$ & + & $\mathrm{R}$ & A & 4 & 5 & 11 & 59 & neck clipping & medial approach \\
\hline 4. & 60 & $\mathrm{~F}$ & + & $\mathrm{L}$ & A & 10 & 13 & 10 & 39 & neck clipping & \\
\hline 5. & 43 & $\mathbf{F}$ & + & $\mathrm{L}$ & $\mathrm{A}$ & 10 & 8 & 9 & 50 & neck ligation & medial approach \\
\hline 6. & 65 & $\mathbf{M}$ & + & $\mathrm{L}$ & A & 17 & 22 & 11 & 35 & neck clipping & \\
\hline 7. & 74 & $\mathbf{F}$ & + & $\mathbf{R}$ & A & 18 & 22 & 17 & 32 & death before surgery & \\
\hline 8. & 50 & $\mathbf{F}$ & + & $\mathrm{L}$ & $\mathrm{A}$ & 13 & 9 & 13 & 49 & death beforc surgery & \\
\hline 9. & 54 & $\mathrm{M}$ & + & $\mathbf{L}$ & A & 9 & 22 & 13 & 43 & neck clipping & shunt \\
\hline 10. & 39 & $\mathbf{F}$ & + & $\mathrm{L}$ & $\mathbf{B}$ & 16 & 13 & 16 & 48 & neck clipping & sitting, shunt \\
\hline 11. & 58 & $\mathbf{F}$ & + & $\mathbf{R}$ & B & 0 & 12 & 6 & 40 & coating & sitting \\
\hline 12. & 51 & $\mathbf{M}$ & + & $\mathbf{L}$ & B & 5 & 10 & 16 & 51 & wrapping \& coating & \\
\hline 13. & 57 & $\mathrm{~F}$ & + & $\mathbf{L}$ & $\mathrm{C}$ & 13 & 1 & 6 & 61 & neck clipping & \\
\hline 14. & 61 & $\mathrm{~F}$ & + & $\mathbf{L}$ & $\mathrm{C}$ & 18 & -4 & 5 & 60 & vertebral artery ligation & \\
\hline 15. & 64 & $\mathbf{M}$ & + & $\mathrm{R}$ & $\mathrm{C}$ & 9 & 8 & 15 & 55 & coating & \\
\hline \multicolumn{12}{|l|}{ Giant } \\
\hline 16. & 53 & $\mathbf{M}$ & - & $\mathbf{L}$ & B & 3 & 16 & 13 & 51 & coating & \\
\hline \multicolumn{12}{|l|}{ Fusiform } \\
\hline 17. & 51 & $\mathrm{~F}$ & + & $\mathbf{R}$ & B & 4 & 5 & 14 & 48 & coating & \\
\hline 18. & 53 & $\mathrm{~F}$ & - & $\mathrm{L}$ & $\mathbf{B}$ & 9 & 6 & 14 & 46 & vertebral artery ligation* & \\
\hline 19. & 43 & $\mathrm{~F}$ & + & $\mathbf{L}$ & $\mathrm{C}$ & 9 & 7 & 9 & 46 & coating & \\
\hline \multicolumn{12}{|l|}{ Peripheral } \\
\hline 20. & 63 & $\mathbf{M}$ & + & $\mathbf{R}$ & & 5 & 17 & 20 & 32 & neck clipping & medial approach \\
\hline 21. & 42 & $F$ & + & $\mathbf{L}$ & & 11 & 15 & 15 & 45 & neck clipping & shunt \\
\hline
\end{tabular}

*Vertebral artery ligation was performed in the intracranial space, immediately proximal to the ancurysmal neck. 


\section{SA C C U L A R \\ A}
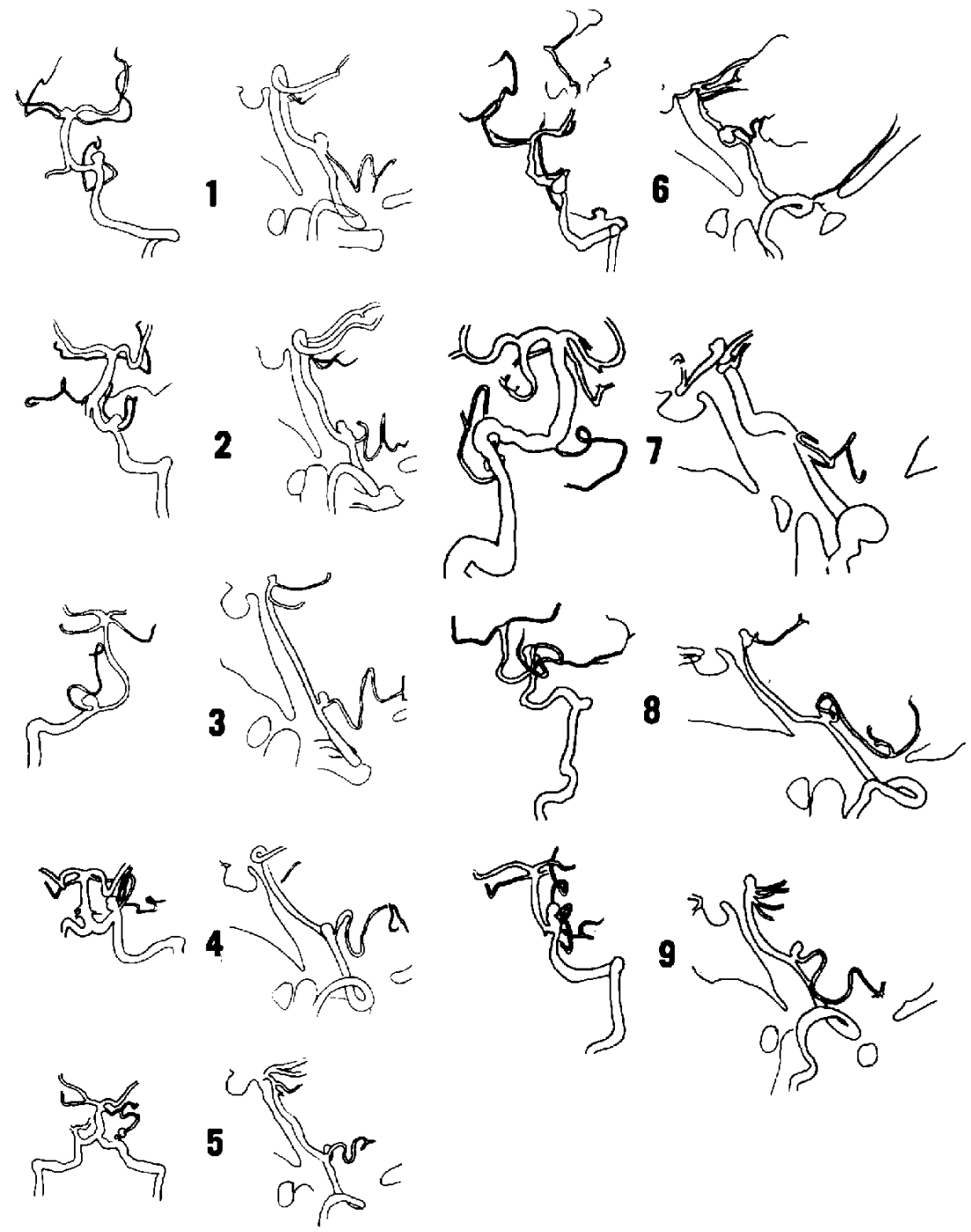

Fig. 1 Tracing of vertebral angiography (saccular aneurysm, Type A, Cases 1-9).

large aneurysms. There were 17 saccular aneurysms including two peripheral posterior inferior cerebellar aneurysms, one giant aneurysm, and three fusiform aneurysms.

The mean age of patients with aneurysms was 54 years, ranging from 31 to 74 . There were seven males and 14 females. The aneurysms were on the left side in 15 cases and on the right side in only six cases.

I. Operative technique of the lateral suboccipital approach

Direct approach to the aneurysm was at- tempted in 18 cases. Timing of the operation was essentially based on the policy of "intentional delayed operation", and was in the second or third week after the subarachnoid hemorrhage. Preoperative status was, by Hunt's grading, Grade 1 in two patients, Grade 2 in six patients and Grade 3 in eight patients. Except for three cases where a sitting position was taken, the operation was carried out with the patient in a prone position with the head slightly rotated towards the side of the aneurysm, or in a supine position with a pillow beneath the shoulder on one side and with the 
B

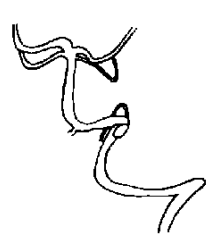

10
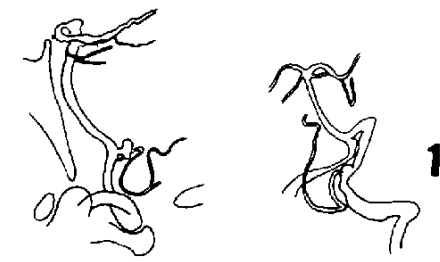

13
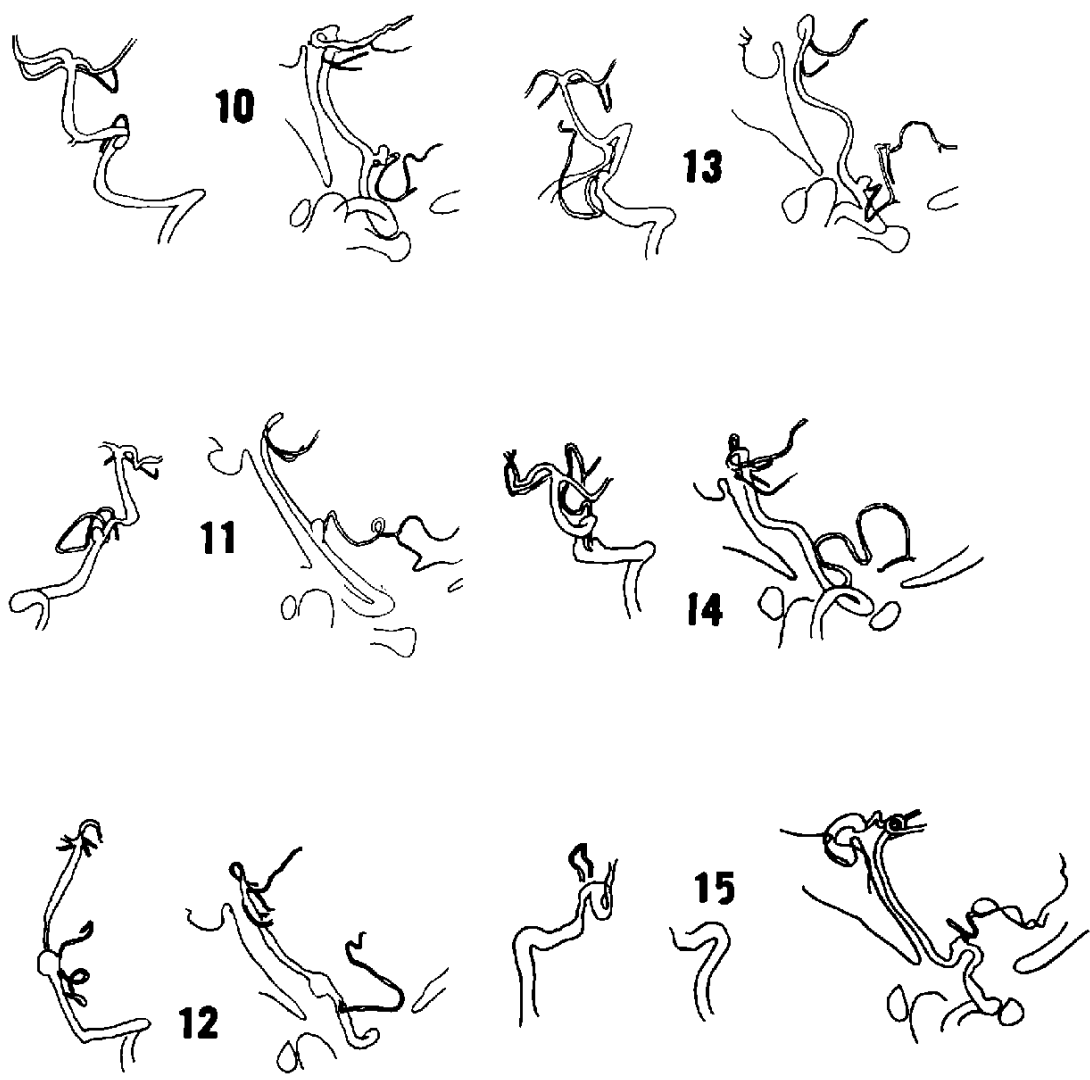

Fig. 2 Tracing of vertebral angiography (saccular aneurysm, Types B and C, Cases 10-15).

head rotated laterally. A unilateral skin flap was turned and the occipital muscle was dissected to expose the inferolateral portion of the occipital bone. Care was taken to remove the bone over the suboccipital region as laterally as possible until the mastoid air cell was opened (Fig. 4). The authors refer to this approach as the lateral suboccipital approach to distinguish it from the traditional posterior or medial suboccipital approach. Using this lateral opening, a visual field approximately parallel to the anterior base of the posterior fossa is obtained with only minimal retraction of the cerebellar hemisphere under a surgical microscope. The sigmoid sinus is followed to the foramen jugulare. The space between the 9th and 10th cranial nerves and the 11th cranial nerve is the route to the vertebral artery, the posterior inferior cerebellar artery and the aneurysm at this site (Fig. 5). The lateral and ventral aspects of the medulla oblongata can be fully observed without any manipulation of vital structures. The first dentate ligament does not disturb the surgeon's vision as is the case in the conventional medial approach.

This lateral suboccipital approach was a method of choice in all cases except for two cases (Cases 3 and 5) and a unique case of fourth ventricle aneurysm (Case 20), where traditional medial suboccipital craniectomy was carried out. Case 14 was another exception and an extracranial ligation of the vertebral artery was performed at the level of $C_{1}$ unwillingly.

\section{Radiometric studies}

Radiometric studies were conducted using 

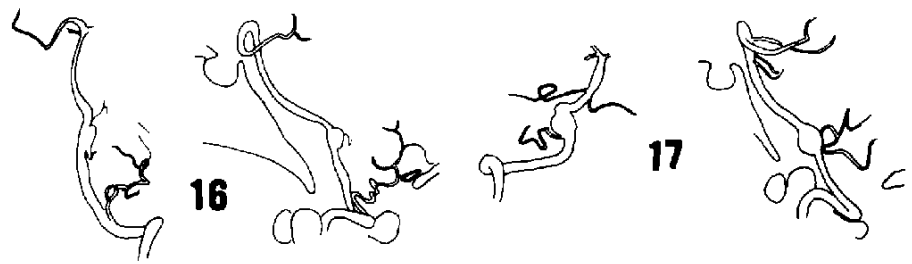

\section{PERIPHERAL}
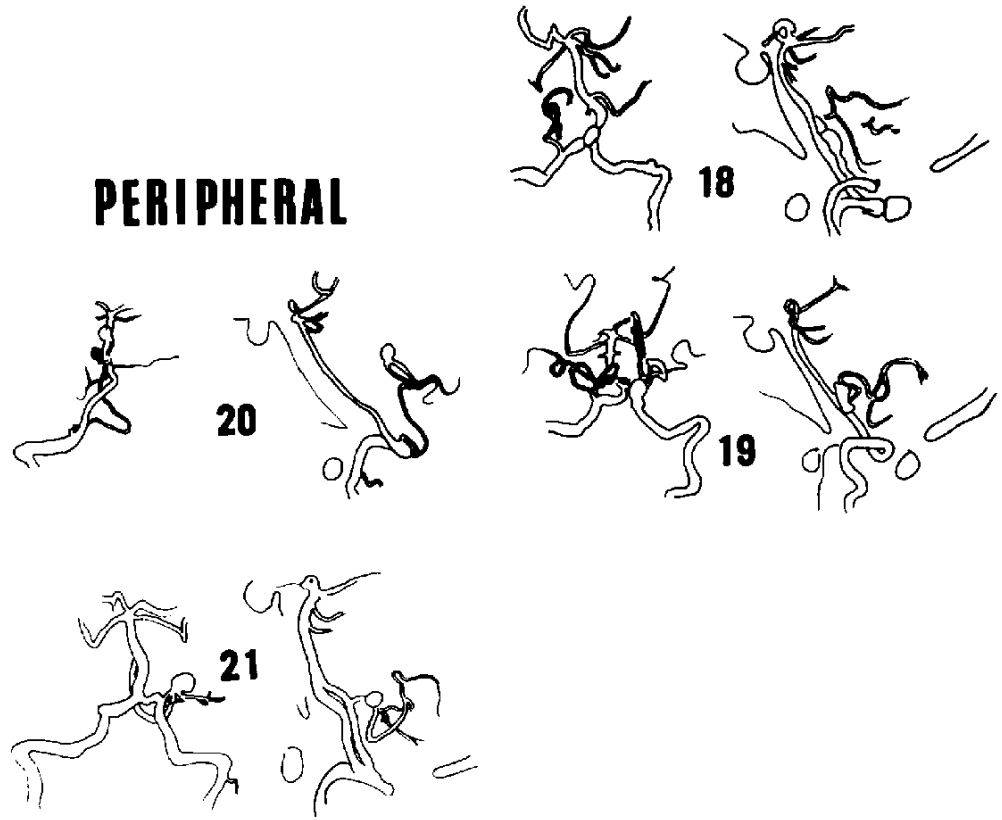

Fig. 3 Tracing of vertebral angiography (giant aneurysm, fusiform aneurysm, peripheral aneurysm, Cases 16-21).

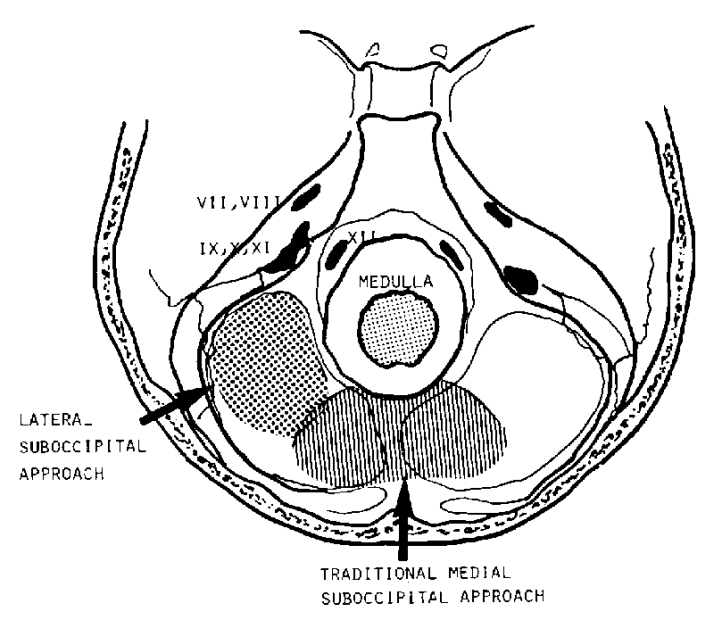

Fig. 4 Schema of suboccipital craniectomy. Lateral suboccipital approach vs traditional medial approach. vertebral angiograms in the aneurysmal cases and in 52 normal subjects. The distances to the neck were three-dimensionally measured from the midline in an anterior-posterior view, from the level of the foramen magnum, from the posterior wall of the clivus and additionally from the tip of the posterior clinoid process in a lateral view (Fig. 6). The midline was defined as that of the skull, regardless of undulations of the basilar artery. In three cases of fusiform aneurysms, the junction between the aneurysm and the proximal vertebral artery was taken for radiometry.

Aneurysmal location was classified into three categories (Fig. 5) in relation to the knee-shaped curving of the vertebral artery in an anterior-posterior view of vertebral angiography: 


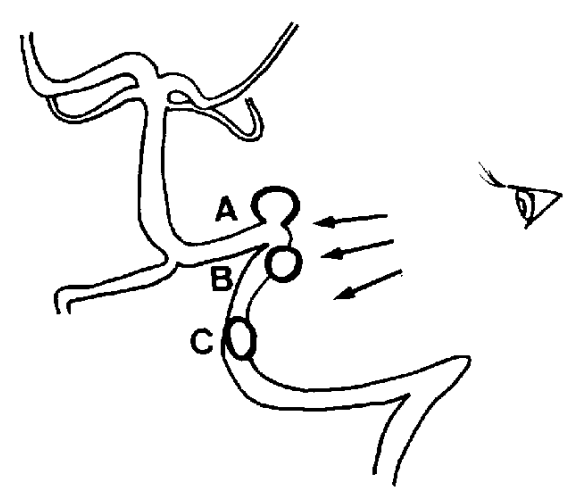

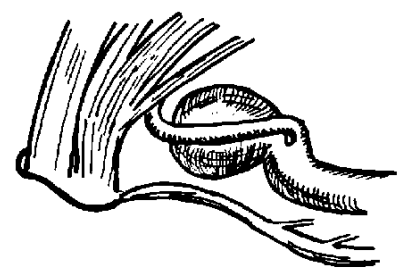

A

9 CASES

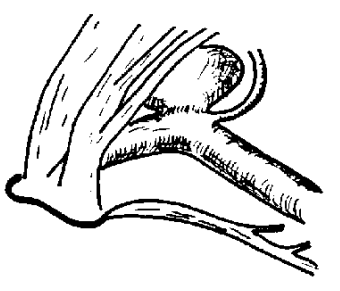

B

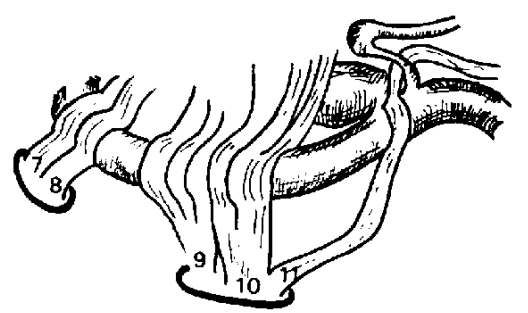

C

4 CASES

Fig. 5 Classification of vertebral-posterior inferior cerebellar aneurysms by their location at the knee portion of the vertebral artery.

A: Aneurysm above the knee, B: Aneurysm below the knee, C: Aneurysm far below the knee of the vertebral artery.
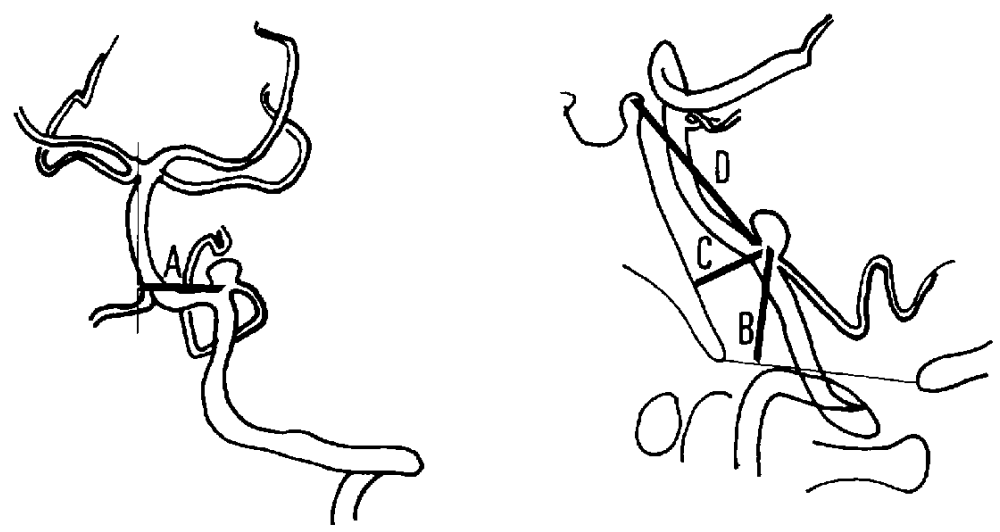

Fig. 6 Radiometric indices. Distance to the aneurysmal neck.

A: From midline, B: From foramen magnum, C: From clivus, D: From posterior clinoid process.

A) The aneurysmal neck is just above the knee of the vertebral artery,

B) just below the knee, or

C) far below the knee of the markedly elongated vertebral artery.
Also the relationship between the aneurysmal neck and the origin and the course of the posterior inferior cerebellar artery was reviewed in each case.

In normal studies, the materials were 52 
pairs of left vertebral angiograms obtained by selective vertebral or retrograde brachial injection of contrast media. These materials were found to be normal without intracranial mass or vascular lesion. Their age distribution was from 20 to 70 years (mean: $49.0 \pm 12.8$ years, $\mathrm{n}=52$ ) with an equal sex ratio. The origin of the posterior inferior cerebellar artery at the vertebral artery and the knee-shaped corner of the vertebral artery were determined in similar measurements of the landmarks in the posterior fossa.

The operative findings during the lateral suboccipital approach were reviewed in relation with radiometric data, and the range of accessibility by this lateral suboccipital approach was analyzed.

\section{Results}

There were two fatal recurrent hemorrhages before definitive surgery. All patients who underwent surgery survived well and functional recovery was satisfactory.

Lower cranial nerves, usually glossopharyngeal and vagal nerves, were impaired preoperatively in seven cases of aneurysms at the origin of the posterior inferior cerebellar artery and such neurological deficits were exaggerated in two cases (Cases 12 and 16) postoperatively (Table 2). New neurological deficits appeared postoperatively in four cases (Cases 1, 5, 9 and 19), but disappeared within several days to weeks. It is noteworthy that one such case (Case 5) was operated on by the traditional medial approach which required retraction of the medulla oblongata; temporary bilateral leg weakness was produced. In two case of peripheral posterior inferior cerebellar aneurysms, there were no neurological dificits before or after surgery.

\section{Aneurysms at the origin of the posterior inferior cerebellar artery}

There were 15 saccular aneurysms, one giant aneurysm and three fusiform aneurysms (Table 1). All aneurysms except one (Case 19) were located dorsal or lateral to the vertebral artery and were not adherent to the dura mater. The most common site of aneurysm was at the knee-shaped corner of the vertebral artery in an anterior-posterior view (Figs. 1-3). The location of the aneurysm was classified as follows (Fig. 5): A) The aneurysmal neck was just above the knee of the vertebral artery in nine cases, B) just below the knee in six cases, and C) far below the knee in four cases. All of three fusiform aneurysms were located below the knee of the vertebral artery. This anatomical classification was quite easily made from a single anterior-posterior view film and was also well correlated with operative observations in the lateral suboccipital approach (Fig. 5). In the case of category (A), the vertebral artery was well visualized proximal to the aneurymal neck, but the distal portion of the vertebral artery was always hidden medial to the aneurysm in our approach. Care should be taken not to clip the distal vertebral artery. In saccular and fusiform

Table 2 Relationship between each radiometric index and incidence of postoperative neurological deficits (vertebral-posterior inferior cerebellar aneurysm)

\begin{tabular}{|c|c|c|c|}
\hline & & Number of patients & $\begin{array}{l}\text { Incidence of } \\
\text { neurological deficits }\end{array}$ \\
\hline $\begin{array}{l}\text { Distance from } \\
\text { midline }\end{array}$ & $\begin{array}{l}0-10 \mathrm{~mm} \\
11-17\end{array}$ & 9000000000 & $\begin{array}{l}4 / 10(40 \%) \\
1 / 4(25 \%)\end{array}$ \\
\hline $\begin{array}{l}\text { Distance from } \\
\text { foramen magnum }\end{array}$ & $\begin{array}{r}1-11 \\
12-23 \\
\end{array}$ & 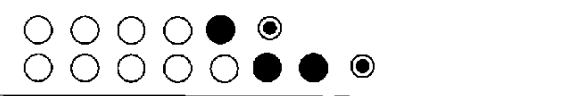 & $\begin{array}{l}2 / 6(33 \%) \\
3 / 8(38 \%)\end{array}$ \\
\hline \multirow[t]{2}{*}{$\begin{array}{l}\text { Distance from } \\
\text { clivus }\end{array}$} & $\begin{array}{r}6-12 \\
13-16 \\
\end{array}$ & 00000 & $\begin{array}{l}1 / 5(20 \%) \\
4 / 9(44 \%)\end{array}$ \\
\hline & & Total & $5 / 14(36 \%)$ \\
\hline
\end{tabular}

$\bigcirc$ : No neurological deficit, deficit, prolonged. 
aneurysms of category (B), the vertebral artery was fully observed proximal to and distal to the aneurysm under a surgical microscope in the space between the 9th, 10th and 11th cranial nerves. There was no risk of involvement of the distal vertebral artery by a clip. Only one giant aneurysm (Case 16) was classified in category (B) by angiography (Fig. 3). Its actual size was unexpectedly large on surgical observation and the distal portion of the vertebral artery was entirely hidden behind the aneurysm. In all four cases of category (C), the vertebral artery was markedly elongated. In Case 12 , the artery was compressing not only cranial nerves 9 th, 10th and 11 th but also 7 th and 8 th laterally.

Radiometric data on the neck of the saccular aneurysms and the proximal end of fusiform aneurysm are listed in Table 1 . There was no significant difference between the mean value of each distance in saccular aneurysms and giant or fusiform aneurysms. There was no correlation between the distances from the midline, from the clivus or from the foramen magnum, but the coefficient of correlation between the distances from the clivus and the level of the foramen magnum was 0.51872 , which was considered significant $(\mathrm{p}<0.05)$. In all 14 cases where the lateral suboccipital approach was attempted, management of the aneurysm was successful by minimal retraction of the cerebellar hemisphere and without any manipulation of the medulla oblongata. Therefore the minimal and maximal values of each distance to the aneurysmal neck, which was successfully managed by lateral suboccipital craniectomy were 0 and $17 \mathrm{~mm}$ from the midline, 1 and $23 \mathrm{~mm}$ from the foramen magnum, 6 and $16 \mathrm{~mm}$ from the clivus, and 35 and 61 $\mathrm{mm}$ from the posterior clinoid process (Table $3)$. None of these aneurysms were considered to have been treated better by a subtemporal transtentorial approach.

The relation between each distance and incidence of postoperative neurological deficits was analyzed (Table 2). The 14 cases where a lateral suboccipital approach was taken for direct surgery were divided into two groups according to the mean value of each distance. The aneurysms which were located within $10 \mathrm{~mm}$ of the midline or at more than $13 \mathrm{~mm}$ from the clivus seemed to be related to deterioration or appearance of neurological deficits, but the distance from the foramen magnum was not related to the results. The location of aneurysms at the knee portion of the vertebral artery was not related to the appearance of neurological deficits.

In all 15 saccular aneurysms, the origin of the posterior inferior cerebellar artery and the course of its main trunk were observed during surgery in relation to the aneurysmal neck and body. The posterior inferior cerebellar artery arose posterior to the aneurysmal neck in eight cases, posterior-lateral in one case, lateral in four cases and posterior-medial in two cases. None of the posterior inferior cerebellar arteries arose medial to or anterior

Table 3 Evaluation of accessibility of the lateral suboccipital approach by radiometric indices (vertebral-posterior inferior cerebellar aneurysm)

\begin{tabular}{|c|c|c|c|c|c|c|c|}
\hline & & & & \multicolumn{4}{|c|}{ Distance to aneurysmal neck (mm) } \\
\hline & & & & $\begin{array}{l}\text { From } \\
\text { midline } \\
8.6 \pm 5.2\end{array}$ & $\begin{array}{c}\text { From } \\
\text { foramen magnum } \\
12.1 \pm 6.7\end{array}$ & $\begin{array}{c}\text { From } \\
\text { clivus } \\
12.2 \pm 3.4\end{array}$ & $\begin{array}{c}\text { From } \\
\text { post. clinoid } \\
46.1 \pm 7.3\end{array}$ \\
\hline \multirow{4}{*}{ Saccular } & $\mathrm{A}$ & 5 & cases & $3 \sim 17$ & $12 \sim 23$ & $10 \sim 15$ & $35 \sim 47$ \\
\hline & B & 3 & & $0 \sim 16$ & $10 \sim 13$ & $6 \sim 16$ & $40 \sim 51$ \\
\hline & $\mathrm{C}$ & 2 & & $9 \sim 13$ & $1 \sim 8$ & $6 \sim 15$ & $55 \sim 61$ \\
\hline & & 10 & cases & $0 \sim 17$ & $1 \sim 23$ & $6 \sim 16$ & $35 \sim 61$ \\
\hline Giant & & 1 & case & 3 & 16 & 13 & 51 \\
\hline \multirow{2}{*}{ Fusiform } & B & 2 & cases & $4 \sim 9$ & $5 \sim 6$ & 14 & $46 \sim 48$ \\
\hline & $\mathrm{C}$ & 1 & & 9 & 7 & 9 & 46 \\
\hline Total & & 14 & cases & $0 \sim 17$ & $1 \sim 23$ & $6 \sim 16$ & $35 \sim 61$ \\
\hline
\end{tabular}


to the aneurysmal neck. Such location facilitates the lateral approach, and the posterior inferior cerebellar artery was well preserved in all cases when clipping was performed. The main trunk of the posterior inferior cerebellar artery was located posterior to the aneurysmal body in eight cases, posterior-lateral in two cases, lateral in four cases, anterior-medial in one case. None took the initial course medial to the aneurysmal body. When the main trunk of the posterior inferior cerebellar artery was located lateral to the aneurysmal body, the course of the posterior inferior cerebellar artery was parallel to the visual axis of the surgeon and care should be taken not to clip the artery. In a giant aneurysm (Case 16) and large fusiform aneurysms (Cases 17 and 18), the posterior inferior cerebellar artery was not confirmed at angiography or at surgery. Case 16 had blood supply from a well developed transdural collateral pathway over the cerebellar hemisphere and a large anterior inferior cerebellar artery seemed to cover the territory of the posterior inferior cerebellar artery in the latter two cases. In another fusiform aneurysm, the origin of the artery was identified by angiography but not confirmed during surgery.

There were three cases associated with congenital vascular anomalies. In Case 6 with an aneurysm at the origin of the left posterior inferior cerebellar artery, the right vertebral artery ended in a well developed right posterior inferior cerebellar artery and Case 19 with a fusiform aneurysm at the origin of left posterior inferior cerebellar artery was associated with a fenestrated vertebral artery on the same side. Such anomalies did not cause any difficulties in surgery but the possible occlusion of the vertebral artery might have resulted in severe brain stem ischemia. In Case 7, angiography and autopsy revealed agenesis of the right internal carotid artery and a ruptured aneurysm at the origin of the left posterior inferior cerebellar artery.

\section{Radiometric studies on normal materials}

The origin of the left posterior inferior cerebellar artery and the knee-shaped corner point of the vertebral artery are described in Table 4.

The location of the origin of the posterior inferior cerebellar artery and the knee of the vertebral artery were observed in 37 subjects. The origin of the artery was higher than the knee-shaped corner point of the vertebral artery in 17 cases $(45.9 \%$ ), which corresponds to category (A) aneurysm cases, at the exact corner point in 13 cases $(35.1 \%)$, and lower than the corner point in seven cases $(18.9 \%)$. Among the latter seven cases, the origin of the artery and the corner point of the vertebral artery were more than $10 \mathrm{~mm}$ apart in three cases $(8.1 \%)$, which corresponds to category (C) aneurysm cases. Four cases were categorized as (B).

In an anterior-posterior view of five cases $(13.5 \%)$, the vertebral artery was straight in its course and the knee-shaped curving was not observed. In three cases $(8.1 \%)$, there was a concave curving towards the left or reverse

Table 4 Distance of origin of the posterior inferior cerebella artery and knee-shaped corner point of the vertebral artery (normal subjects)

Distance $(\mathrm{mm})$

\begin{tabular}{|c|c|c|c|c|}
\hline & $\begin{array}{c}\text { From } \\
\text { midline }(\mathrm{mm})\end{array}$ & $\begin{array}{c}\text { From } \\
\text { foramen } \\
\text { magnum }(\mathrm{mm})\end{array}$ & $\begin{array}{c}\text { From } \\
\text { clivus }(\mathrm{mm})\end{array}$ & $\begin{array}{c}\text { From } \\
\text { posterior } \\
\text { clinoid }(\mathrm{mm})\end{array}$ \\
\hline $\begin{array}{l}\text { Origin of the } \\
\text { posterior } \\
\text { inferior cerebellar } \\
\text { artery }\end{array}$ & $\begin{array}{c}10.4 \pm 4.8 \\
(2.0 \sim 20.7) \\
N=49\end{array}$ & $\begin{array}{c}12.1 \pm 7.0 \\
(-9.1 \sim 28.0) \\
N=47\end{array}$ & $\begin{array}{c}12.5 \pm 4.0 \\
(6.8 \sim 22.4) \\
N=47\end{array}$ & $\begin{array}{c}46.2 \pm 9.7 \\
(27.7 \sim 78.6) \\
N=47\end{array}$ \\
\hline $\begin{array}{l}\text { Knee-shaped } \\
\text { corner point } \\
\text { of the vertebral } \\
\text { artery }\end{array}$ & $\begin{array}{c}12.4 \pm 4.1 \\
(5.2 \sim 22.5) \\
\mathrm{N}=45\end{array}$ & $\begin{array}{l}12.5 \pm 5.1 \\
(3.4 \sim 23.3) \\
N=41\end{array}$ & $\begin{array}{c}13.6 \pm 3.5 \\
(6.8 \sim 20.5) \\
N=41\end{array}$ & $\begin{array}{c}46.4 \pm 6.1 \\
(37.3 \sim 58.7) \\
N=41\end{array}$ \\
\hline
\end{tabular}


knee-shaped curving, instead of convex curving as in other cases. There were no cases with such a course of the vertebral artery among the aneurysm cases.

\section{Peripheral posterior inferior cerebellar aneurysms}

There were two such cases and both were saccular. Case 21 was at the lateral medullary segment where the left posterior inferior cerebellar artery divides into tonsillohemisheric and vermian branches. The aneurysmal neck was located $11 \mathrm{~mm}$ from the midline, $15 \mathrm{~mm}$ above the foramen magnum, $15 \mathrm{~mm}$ posterior to the clivus and $45 \mathrm{~mm}$ below the posterior clinoid process. The lateral suboccipital route offered an easy approach for successful neck clipping. Another aneurysm (Case 21) was at the unusual location of the right posterior inferior cerebellar artery. ${ }^{15}$ ) The aneurysm was located entirely in the fourth ventricle at the tip of a markedly elongated supratonsillar segment. The traditional posterior or medial approach was the method of choice and successful neck clipping was carried out after splitting the inferior vermis. The aneurysmal neck was measured as $5 \mathrm{~mm}$ from the midline, $20 \mathrm{~mm}$ posterior to the clivus, $17 \mathrm{~mm}$ above the foramen magnum and $32 \mathrm{~mm}$ below the posterior clinoid process. Both of these patients resumed a normal life.

\section{Discussion}

It is generally believed and quoted in the literature that Schwartz $^{12)}$ first successfully operated on an aneurysm of the vertebrobasilar system in 1946 and that this was followed by Rizzoli et al., who operated on a left posterior inferior cerebellar aneurysm in $1947 .{ }^{10)}$ Among 28 cases of posterior fossa aneurysms reported by Höök et al. in 1968, there was a case of a right peripheral posterior inferior cerebellar aneurysm which was successfully trapped and excised by Olivecrona as early as 1932. ${ }^{7}$ Olivecrona should be considered as the first surgeon to operate on an aneurysm of the posterior fossa successfully.

In 1957, prior to the operation, DeSaussure et al. made a diagnosis of a saccular aneurysm of the posterior inferior cerebellar artery by percutaneous vertebral angiography in two patients. $^{3)}$ The method of choice by such pioneers was "entrapment" of the aneurysm between two clips and none of them succeeded in neck clipping or ligation with preservation of normal vasculature. ${ }^{3,7,10,12)}$ There were premature ruptures of the aneurysm during surgery in four out of five cases reported above $\mathrm{e}^{3,10,12)}$ and the postoperative courses were eventful.

Introduction of vertebral angiography in neurosurgery and technical improvements in the use of the surgical microscope have allowed definitive treatment on aneurysms of the posterior circulation. The posterior inferior cerebellar artery is the second most common site of aneurysms in the posterior fossa and the attention of neurosurgeons has increasingly focused on these aneurysms. ${ }^{1,4,9)}$ However, a direct approach on the aneurysms at this site is still considered difficult because of the vital structures of the brain stem and lower cranial nerves near by and probably because the experiences of any individual neurosurgeon are limited due to its rarity. The diverse locations of such aneurysms have been pointed out by Drake $^{5)}$ and Pia, ${ }^{9)}$ but a precise anatomical description based on radiometric studies has been lacking for such series. This is undoubtedly one of the reasons why neurosurgeons were unable to discuss accessibility by different approaches with the same scale. The purpose of this study has been to provide a radiometric description of the posterior inferior cerebellar aneurysm and a discussion of the accessibility of these aneurysms in the light of such measurements.

\section{Aneurysms at the origin of the posterior inferior cerebellar artery}

Surgical technique: Because of the wide variety of aneurysmal locations in the posterior fossa, various surgical approaches have been advocated for the treatment of aneurysms at the origin of the posterior inferior cerebellar artery. ${ }^{5)}$ Drake $^{5)}$ summarized them into the three categories of the traditional suboccipital approach, subtemporal transtentorial approach and transoral transclival approach. He stated that, for those located laterally, conventional suboccipital craniectomy should offer sufficient surgical space and a subtemporal transtentorial approach would be possible for a few which 
are located at a particularly high level of the posterior fossa. In the case of aneurysms located within a centimeter of the midline and behind the lower third of the clivus, an area which he called a "no man's land", the transoral transclival route is the only possible approach. ${ }^{5}$ ) The risk of cerebrospinal fluid leakage and consequent meningitis was reported with considerable mortality. ${ }^{14)}$ A method alternative to the anterior approach is the transcervical transclival approach, but this requires transection of multiple muscular and neural structures at the neck. ${ }^{2)}$

In his textbook, $\mathrm{Kempe}^{8)}$ provided an illustration of the traditional bilateral suboccipital craniectomy under a midline skin incision in which a medial portion of the occipital bone, the posterior arch of the atlas and a part of the $C_{2}$ lamina were also removed with the patient in a sitting position. In this approach, heavy retraction of the cerebellar hemisphere in the medial-superior direction is required to expose the vertebral artery under the uppermost dentate ligament. The surgeon's visual axis is inevitably in the posterior-inferior direction and the lower cranial nerves and the medulla oblongata must be displaced to reach the aneurysmal neck. This was true in our experience in two exceptional cases (Cases 3 and 5). The medulla oblongata was retracted to expose the aneurysmal neck and weakness of the legs appeared postoperatively although it did not last for a long time (Case 5). Premature aneurysmal rupture during surgery was experienced in only one case (Case 3) where this traditional medial suboccipital craniectomy was used and heavy retraction was applied to the cerebellum. Kempe's description was based on his early, limited experiences of aneurysms at this location.

Drake $^{4)}$ took a similar posterior approach when the neck of the aneurysm arose a centimeter or so to one side of the midline. It was necessary to divide the first dentate ligament and to retract the medulla oblongata to follow the vertebral artery and to visualize the aneurysm between the 11th and 12th cranial nerves. He recommended use of spontaneous respiration as a guide with regard to retractor pressure.

In our technique, the inferior-lateral portion of the suboccipital region was removed after turning a unilateral skin flap with the lateral limb at the mastoid. By this skin incision, dissection of muscle is sufficient and muscle mass does not block the surgeon's vision as was found in Drake's series. ${ }^{5)}$ Removal of the $\mathrm{C}_{1-2}$ lamina was not required. The cerebellar hemisphere was lightly retracted posteriorly to gain sufficient space between the anterior base of the posterior fossa and the cerebellum. The authors refer to this as a lateral suboccipital approach. The lateral and ventral aspects of the medulla oblongata were easily observed without any retraction and the lower cranial nerves were not disturbed during dissection of the aneurysm.

A blade of the clip was easily placed between the posterior inferior cerebellar artery and the aneurysmal neck and another blade was inserted between the neck and the vertebral artery. The take-off and the course of the posterior inferior cerebellar artery seem to be safely manageable by the lateral approach because in most cases the posterior inferior cerebellar artery is posteriorly separate from the aneurysmal neck and its body. The bulging of the jugular tubercle never blocked the approach to the aneurysm.

Radiometric study: There is no question that the location of the aneurysm determines the difficulty of access to the crucial point in the posterior fossa. To our knowledge, there has previously been no report which is specifically concerned with this point in radiometric studies. An aneurysm which is located at or close to the midline, far from the clivus, and also very high from the level of the foramen magnum is inevitably difficult to manage through a traditional suboccipital approach. The distance to the aneurysmal neck from each landmark was considered as an adequate index to indicate the depth of the visual field and the degree of retraction on the cerebellum. By this lateral suboccipital approach, direct management of the aneurysm was successful in all of the attempted cases. Retraction on the cerebellar hemisphere was very light and the space between the 9th, 10th and 11th cranial nerves was wide enough to observe the posterior inferior cerebellar artery, the vertebral artery, the aneurysm, the 12th cranial nerve and the medulla oblongata. There was no mortality 
and no postoperative permanent neurological deficits. Aneurysms located on the midline or within $10 \mathrm{~mm}$ of the midline, $16 \mathrm{~mm}$ from the clivus and $23 \mathrm{~mm}$ above the foramen magnum, were found to be within the range of successful management under the surgical microscope. All such aneurysms were located over the lower third of the clivus or at the border line of the middle and the lower third of the clivus. There were no postoperative deaths, but the postoperative neurological deficits seemed to be related to the location of the aneurysm. The risk of postoperative neurological deficits should be considered in aneurysms which are located within $10 \mathrm{~mm}$ of the midline or more than $13 \mathrm{~mm}$ from the clivus.

Categorization of the aneurysmal location in relation to the knee of the vertebral artery was useful. It is very simple to determine such anatomical relation in a single anterior-posterior view film and it gives important information concerning how to apply a clip to the neck. The vertebral artery proximal to and distal to the aneurysmal neck was well visualized in the surgical field in categories (B) and (C), but aneurysms of category (A) were different. Care should be paid not to include the distal portion of the vertebral artery, hidden medial to the aneurysm, in clipping. Drake, ${ }^{5)}$ who took a more posterior route, stated that the hidden part of the vertebral artery could be visualized by holding the aneurysm closed with forceps or by allowing the blades of the clip to close slowly to collapse the neck so that they can then be realigned and positioned correctly just before the final closure. This method could be used even in our approach in an aneurysm of category (A). In this respect, our simple categorization was quite useful. Drake also pointed out that since the posterior inferior cerebellar artery emerges from the near side of the neck, clipping is often awkward. This anatomical relation of the origin of the posterior inferior cerebellar artery and the aneurysmal neck is another reason for using the lateral approach. Scialfa et al. ${ }^{13)}$ observed 49 normal posterior inferior cerebellar arteries, of which only eight originated from the medial wall of the vertebral artery. There was no case of aneurysms where the posterior inferior cerebellar artery was located medial to the neck of the aneurysm and the vertebral artery. These findings are also thought to indicate surgery by means of the lateral approach.

Radiometric studies on normal subjects were conducted on the origin of the posterior inferior cerebellar artery from the vertebral artery and the knee-shaped corner point of the vertebral artery. This was quite useful for recognizing how far the individual aneurysm at this site is from the normal position. $\mathrm{Pia}^{9)}$ pointed out the extraordinary variability of the site of origin of the posterior inferior cerebellar artery from the entrance of the vertebral artery into the dura mater below the first dentate ligament until close to the vertebrobasilar junction. However, his observations were made, in relation to the vertebral artery or the basilar artery which were variable with respect to their own location in the posterior fossa. Scialfa et al. ${ }^{13)}$ observed the location of the origin of this artery in relation to the level of the olive, but since there is no external landmark to show the site of the olive, this cannot be helpful to surgeons. Our radiometric studies were performed to determine absolute measurements at the site of the artery in the space of the posterior cranial fossa; the range of possible variations was thereby clearly demonstrated.

\section{The peripheral posterior inferior cerebellar aneurysm}

An aneurysm located at the peripheral segment of this artery is rare. $\mathrm{Pia}^{9)}$ classified 12 cases, including his own three cases, into three groups: five cases located at the proximal medullary segment, three at the main junction (choroidal arch) and three others at the peripheral branches. Our two cases fall into his first and second groups, respectively. Case 21 of an aneurysm at the proximal medullary segment was easily managed by the lateral suboccipital approach and the unique case of an aneurysm in the fourth ventricle was managed by the traditional posterior or medial approach (Case 20). ${ }^{15}$ )

\section{References}

1) Bull, J. W. D.: Contribution of radiology to the study of intracranial aneurysm. $\mathrm{Br} \mathrm{Med} \boldsymbol{J}$ 2: 1701-1708, 1962. 
2) Fox, J. L.: Obliteration of midline vertebral artery aneurysm via basilar craniectomy. $J$ Neurosurg 26: 406-412, 1967.

3) DeSaussure, R. L., Hunter, S. E. and Robertson, J. T.: Saccular aneurysms of the posterior fossa. $J$ Neurosurg 15: 385-391, 1958.

4) Drake, C. G.: Transoral transclival approach. pp 787-806, In Youmans, J. R. (ed): "Neurological Surgery. Vol. 2." Saunders, Philadelphia, London, Toronto, 1973.

5) Drake, C. G.: Treatment of aneurysms of the posterior cranial fossa. Prog Neurol Surg 9: 122-194, 1978.

6) Greitz, T. and Löfstedt, S.: The relationship between the third ventricle and the basilar artery. Acta Radiol 42: 85-100, 1954.

7) Höök, O., Norlén, G. and Guzman, J.: Saccular aneurysms of the vertebral-basilar arterial system. A report of 28 cases. Acta Neurol Scand 39: 271-304, 1968.

8) Kempe, L. G.: "Operative Neurosurgery. Vol. 2." Springer-Verlag, Berlin, Heidelberg, New York, 1970, pp 66-71.

9) Pia, H. W.: Classification and treatment of aneurysms of the vertebro-basilar system. Neurol Med Chir 19: 575-594, 1979.
10) Rizzoli, H. V. and Haynes, G. J.: Congenital berry aneurysm of the posterior fossa. Case report with successful operative excision. $\checkmark$ Neurosurg 10: 550-551, 1953.

11) Rothman, S. L. G., Azar-Kia, K., Kier, E. L., Schechter, M. M. and Allen, W. E., III.: The angiography of posterior inferior cerebellar artery aneurysms. Neuroradiology 6: 1-7, 1973.

12) Schwartz, H. G.: Arterial aneurysm of the posterior fossa. $J$ Neurosurg 5: 312-316, 1948.

13) Scialfa, G., Ruggiero, G., Salamon, G. and Michotey, P.: Postmortem investigation of the vertebrobasilar system. Acta Radiol [Suppl] 347: 259-269, 1976.

14) Yamaura, A., Makino, H., Isobe, K., Takashima, T., Nakamura, T. and Takemiya, S.: Repair of the cerebrospinal fluid fistula following transoral transclival approach to a basilar aneurysm. Technical Note. $J$ Neurosurg 50: 834-836, 1979.

15) Yamaura, A., Isobe, K., Nakamura, T., Ono, J. and Makino, H.: A peripheral posterior inferior cerebellar aneurysm located in the fourth ventricle. Surg Neurol 13: 297-299, 1980. 